\title{
Guidelines for Need-Supportive Coach Development: The Motivation Activation Program in Sports (MAPS)
}

\author{
Hedda Berntsen \\ Norwegian School of Sport Sciences \\ Elsa Kristiansen \\ University of South-Eastern Norway
}

\begin{abstract}
The purpose of this article is to share the conceptual framework, design, and impact evidence of a coach development program that was aimed at teaching coaches how to act need-supportive toward their athletes. Informed by Self-Determination Theory, the Motivation Activation Program in Sports (MAPS) was developed to contribute a coach interpersonal-style perspective to the Norwegian Ski Federation education system. The program was delivered at the Norwegian College of Elite Sport throughout the 2016/2017 season as a test trial. This article is organized into three sections. First, a detailed description of the conceptual framework used to inform MAPS is offered. Next, a thorough description of MAPS building components is provided. The third section of the article presents impact evidence of coaches' learning experiences together with coaches' practice examples of needsupportive coaching skills. Results reveal that MAPS taught coaches about need-supportive skills at the intrapersonal (awareness of own coaching practice) and interpersonal (interaction with athletes) level. In addition, effective need-support for athletes required sufficient time for each athlete, a gradual approach to athlete understanding, and a thorough consideration of specific situations.
\end{abstract}

Keywords: coach education, interpersonal skills, need-supportive coaching skills, young athletes

Coaches play an important role in their athletes' sport participation experiences, and they are often responsible for shaping athletes' social environment (Gilbert \& Trudel, 2004; Matosic, Ntoumanis, \& Quested, 2016). Self-Determination Theory (SDT; Ryan \& Deci, 2017) distinguishes between two distinctly different interpersonal styles that influence athlete experiences in very different ways - need-supportive and controlling styles (Ntoumanis, 2012). These styles are orthogonal (Matosic \& Cox, 2014), and coaches tend to use a combination of controlling and supportive behaviors. A predominantly supportive style is associated with athlete well-being and adaptive athlete outcomes (Ntoumanis, 2012), whereas a predominantly controlling style is associated with athlete ill-being and maladaptive functioning (Vansteenkiste \& Ryan, 2013). A need-supportive coaching style is highly recommended for young elite athletes' well-being and long term competitive participation (Balaguer et al., 2012; González, Tomás, Castillo, Duda, \& Balaguer, 2017; Kristiansen \& Roberts, 2010; Ntoumanis, 2012).

Coach development programs (CDP) can change coaches' interpersonal, intrapersonal and professional behaviors through education, social interaction, and/or personal reflection when learning activities are systematically applied (Evans, McGuckin, Gainforth, Bruner, \& Côté, 2015; Lefebvre, Evans, Turnnidge, Gainforth, \& Côté, 2016; Smith, Smoll, \& Cumming, 2007). Current reviews suggest that the quality of coach education can be improved when CDPs focus on: (a) coaches' interpersonal knowledge (Lefebvre et al., 2016) and (b) developing and implementing CDPs that are grounded in theory (Allan, Vierimaa,
Gainforth, \& Côté, 2017; Evans et al., 2015). Lefebvre et al. (2016) classified CDPs into three main categories in their 2016 review. The majority of the 285 CDPs focused on coaches' professional knowledge development such as technical and tactical skills. Only 18 programs focused on coaches' interpersonal knowledge, while six programs focused on coaches' intrapersonal knowledge, revealing that both areas are underrepresented in coach education.

The second area of improvement for coach education is the use of theory informed CDPs. Several reviews have concluded there is a need for CDPs that are grounded in behavioral change theories (Allan et al., 2017; Evans et al., 2015; Lefebvre et al., 2016). Turnnidge and Côté (2017) suggest integrating interpersonal theories into coach education both to explore the interpersonal dimension of coach-athlete interactions and to design effective, interpersonally-focused CDPs. Self-determination theory (Ryan \& Deci, 2017) is one such theory. Despite rigorous empirical testing of SDT, effectiveness of the application of autonomy-supportive behaviors is currently unknown to coach education (Vella \& Perlman, 2014).

Recently, an attempt to gain knowledge on the effectiveness of the application of autonomy-supportive behaviors to coach education suggests more focus is needed on specific examples of how to implement autonomy-supportive coaching behaviors (Langdon, Harris, Burdette III, \& Rothberger, 2015). One CDP design with the aforementioned in mind is the Motivation Activation Program in Sports (MAPS). MAPS was developed to add a coach interpersonal-style perspective to the Norwegian Ski Federation's educational system and ultimately, if evaluated as meaningful, 
part of The Norwegian Olympic and Paralympic Committee and Confederation of Sports. MAPS was implemented at one of the Norwegian College of Elite Sport (NTG) schools in the 2016/2017 season. This elite sport school offers a unique research context in the sense that it has been highly successful-former and present NTG students have won 77 Olympic medals and 186 World Championship medals since the beginning of the 1990s (Norges Toppidrettsgymnas, 2018). In the present article, we describe coaches' learning experiences with MAPS.

The aim of this article is to present a detailed description of the conceptual framework used to inform MAPS, share a thorough description of MAPS components and design, and present impact evidence of coaches' learning experiences.

\section{Conceptual Framework Used to Inform MAPS}

The purpose of MAPS was to train coaches on how to create a more need-supportive sport context for their athletes, ultimately leading to athletes' autonomous functioning, performance, and well-being. SDT is of great interest for MAPS because one of its central tenets is that the quality of social contexts influences the motivation, performance, and wellness of the people in those contexts (Deci \& Ryan, 1985; Ryan \& Deci, 2017). By merging the extended version of the coach-athlete motivational model (Mageau \& Vallerand, 2003) with the complete SDT causal sequence (Fortier, Duda, Guerin, \& Teixeira, 2012; Grouzet, Vallerand, Thill, \& Provencher, 2004; Vallerand, 1997; Vallerand, Fortier, \& Guay, 1997; Vallerand \&
Losier, 1999) the SDT process model of coach need-support influence on sport participation and adaptive outcomes was created (see Figure 1).

The model is based on the assumption that coach behaviors influence athletes' motivation through their direct impact of athletes' three basic psychological needs. The degree of needsatisfaction will determine to what extent athletes exhibit autonomous sports participation motivation. One of the key postulates of SDT is that the quality of athletes' motivation will influence athlete outcomes, such as performance and well-being (Deci \& Ryan, 2000; Mageau \& Vallerand, 2003; Ryan \& Deci, 2017). In addition to postulating the difference between intrinsic (something is enjoyable in itself) and extrinsic motivation (external incentive is needed to act), SDT distinguishes between autonomous (doing something by choice and for pleasure) and controlled (doing something out of a sense of obligation or pressure) forms of motivations (Grouzet et al., 2004). The most positive outcomes are derived from autonomous forms of motivation (intrinsic or self-determined extrinsic motivation) (Vallerand, Pelletier, \& Koestner, 2008). For example, autonomously functioning athletes have been reported to make greater effort (Smith, Ntoumanis, Duda, \& Vansteenkiste, 2011) and persist longer (Calvo, Cervello, Jimenez, Iglesias, \& Murcia, 2010) than controlled (non-selfdetermined extrinsic motivation) functioning athletes.

A consideration of the three basic psychological needs of autonomy (the need to feel ownership in sports participation), competence (having a sense that one masters the drills and exercises) and relatedness (feeling related to the coach and teammates) is critical to understanding how to foster optimally

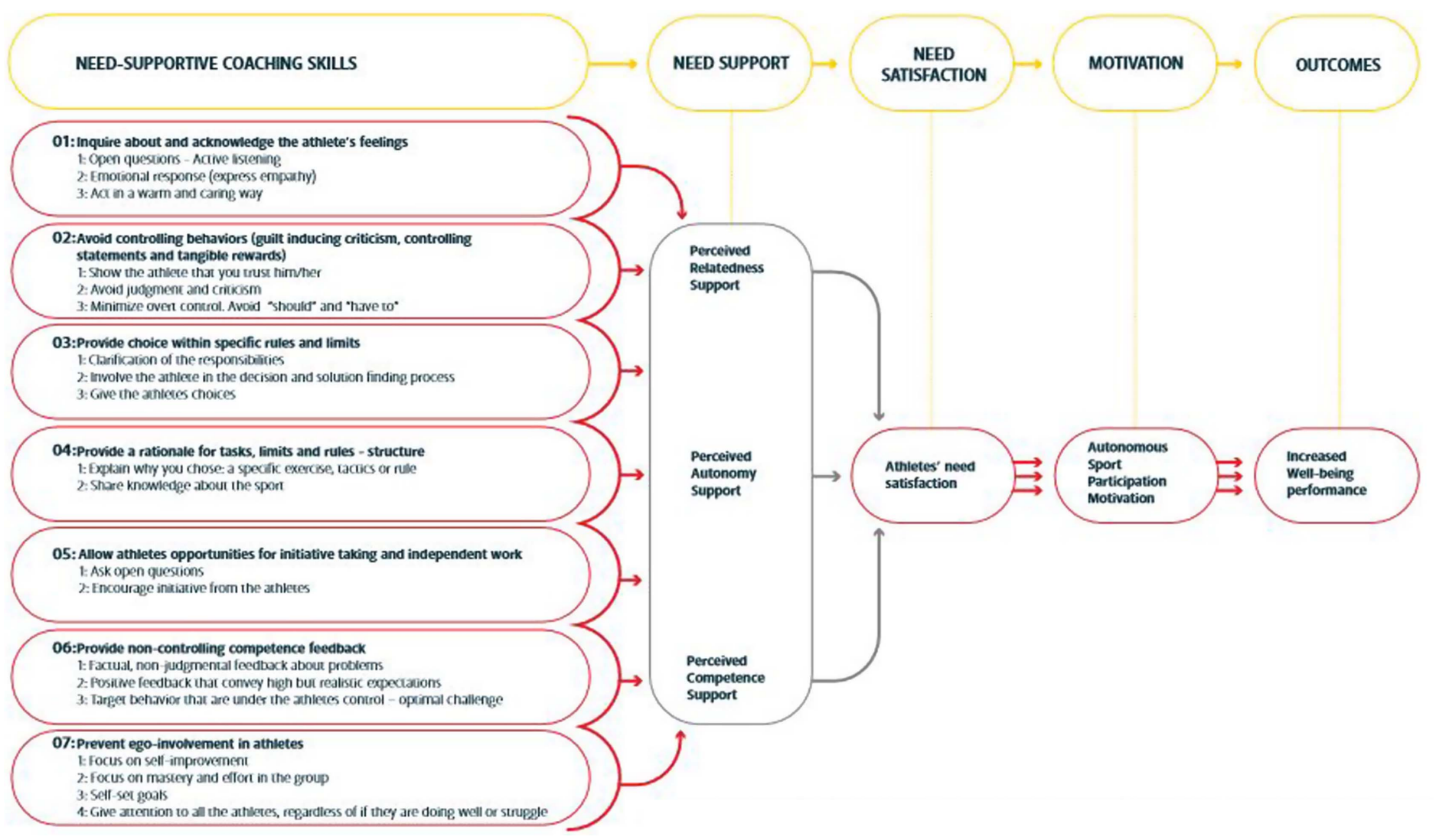

Figure 1 - SDT process model of coach need-supportive behaviours influence on sport participation motivation and well-being. 
functioning and flourishing athletes (Deci \& Ryan, 2000, 2002; Matosic et al., 2016). Parents, coaches, teammates, and administrators make up athletes' social environment, and they can support or thwart athlete's needs (Ryan \& Deci, 2017). Athletes can also be active agents in their own need satisfaction (Reeve, 2013).

Typically, a need-supportive interpersonal coaching style supports all three athlete needs (Ntoumanis, 2012; Taylor \& Ntoumanis, 2007; Tessier, Sarrazin, \& Ntoumanis, 2010). These need-supportive coach behaviors include autonomy support accompanied by appropriate structure (competence support) and interpersonal involvement strategies (relatedness support) (Mageau \& Vallerand, 2003; Matosic et al., 2016; Taylor \& Ntoumanis, 2007). Based on the assumption that athletes may benefit from autonomy support accompanied by a well-structured sport context and the presence of high interpersonal involvement, as shown in the physical education context (Jang, Reeve, \& Deci, 2010; Tessier, Sarrazin, \& Ntoumanis, 2010), MAPS was developed specially around teaching coaches how to support their athletes' basic psychological needs. A set of explicit 'how to' skills was drawn from self-determination theory and research, which resulted in a toolbox for coaches (see need-supportive coaching skills Figure 1 and Table 1).

\section{How to Act Need-Supportive-Explicit Skills}

Autonomy-support, involvement-promoting strategies and structure often co-occur (Aelterman et al., 2013; Reeve \& Jang, 2006). Equally, because the autonomy-supportive coaching strategies presented by Mageau and Vallerand (2003) have been shown to have a multiple needs effect (supporting more than one need at once), they were considered a good starting point for developing a set of explicit need-supportive coaching skills for MAPS. A detailed description of the need supportive strategies and explicit skills that informed the content of MAPS is offered below.

\section{Inquire about and acknowledge athletes' feelings}

This strategy supports athletes' need for relatedness and autonomy (Mageau \& Vallerand, 2003). By taking an interest in their athletes' life and feelings through open questions and active listening, coaches can convey their involvement (Sparks, Dimmock, Whipp, Lonsdale, \& Jackson, 2015; Tessier et al., 2010). Emotional support can be given by showing emotional response and acting in a warm and caring way in response to athlete's expressions (Skinner \& Edge, 2002; Tessier et al., 2010).

\section{Supportive behaviors (Avoid controlling behaviors)}

Controlling behavior pressures the athletes to think and behave in certain ways (Deci \& Ryan, 1985), and this restrains their autonomy (Deci \& Ryan, 2000). In contrast, supportive behaviors can create a trusting context in which the athlete feels cared about and in which her or his relatedness need is supported (Tessier et al., 2010). Explicitly, the coach can convey trust by behaving sympathetic, warm, and affectionate (Skinner \& Edge, 2002). By avoiding judgement and criticism and minimizing overt control (should, have to), athletes can feel supported both in terms of relatedness and in a context that allows them to feel ownership and act for self-determined reasons (Mageau \& Vallerand, 2003; Reeve, Jang, Carrell, Jeon, \& Barch, 2004).

3. Provide choice within specific rules and limits

Coaches can add structure when clarifying athlete responsibilities (Matosic et al., 2016) by being transparent about coach expectations and the consequences of athlete behavior (Taylor \&
Ntoumanis, 2007). Another explicit skill is to involve the athlete in decision and solution finding processes (Amorose, 2007; Standage, Gillison, \& Treasure, 2007). When providing choices, it is vital that the athletes perceive them as real choices (Amorose \& AndersonButcher, 2007; Standage et al., 2007) because having choice is important for the athlete's experience of volition in relation to her or his sport participation (Matosic \& Cox, 2014).

\section{Provide a rational for task, limits and rules - structure}

This strategy supports both autonomy and competence. When a coach explains why he/she chose a specific exercise, tactic, or rule, it clarifies the reason behind it, allowing the athlete to internalize the meaningfulness of the activity and feel selfdetermined (Mageau \& Vallerand, 2003). Structure comes in the form of the coach giving information about plans and goals in an appropriately structured environment (Jang, Reeve, \& Deci, 2010; Matosic et al., 2016). This can happen for example when a coach shares knowledge about the sport and how it relates to the plan and chosen skill building activities.

\section{Allow athlete opportunities for initiative taking and indepen- dent work}

This fifth strategy is a predominantly autonomy support strategy. To be successful at facilitating perceptions of autonomy, coaches are encouraged to ask open questions to their athletes to have a better idea about athletes' ideas about their developmental process (Amorose, 2007; Stone, Deci, \& Ryan, 2009). Central to this strategy is that coaches encourage initiative concerning athletes sport participation (Mageau \& Vallerand, 2003; Stone et al., 2009).

\section{Provide non-controlling competence feedback}

As the phrase indicates, this is a cardinal competence supportive strategy, as the informational aspect (rather than controlling) of the activity informs athletes about their competence (Mageau \& Vallerand, 2003). Coaches can give factual non-judgmental feedback about problems (Ryan \& Deci, 2017; Tessier et al., 2010) to facilitate competence satisfaction. When offering contingent feedback in an autonomy supportive way, it relates back to athletes' endeavors and this can influence their feeling of competence and autonomy, as it is self-organized (Deci \& Ryan, 2000). The feedback needs to be high in competence-related information and be constructive (Jang et al., 2010). Further, positive feedback that conveys high but realistic expectations (Amorose, 2007; Carpentier \& Mageau, 2013; Tessier et al., 2010), informs athletes about their sports participation and fosters skill development. Appropriate expectations can facilitate athletes' confidence that they can meet the challenges of the sport (Matosic et al., 2016). Positive feedback supports the competence need directly (Ryan \& Deci, 2017). Also, central for athletes to feel competent is to target behaviors that are under the athletes' control by providing a challenging task (optimal) (Deci \& Ryan, 2000; Tessier et al., 2010). When challenges are optimal, the athlete experiences a feeling of competency (Deci \& Ryan, 2000; Matosic et al., 2016). This is also an autonomy-supportive strategy in the sense that it allows for athletes' self-organization in their sport endeavors (Deci \& Ryan, 2000).

\section{Facilitate self-improvement focus (prevent ego-involvement)}

Ego-oriented environments tend to pressure athletes into situations and coach dictated activities to prove themselves worthy. Athletes no longer feel free to choose activities of interest and their sense of self-determination is reduced (Mageau \& Vallerand, 2003). One explicit behavior coaches can use to facilitate selfimprovement focus and prevent ego-involvement is to provide 
Table 1 Coach Learning Experiences Following MAPS

\section{Need-Supportive \\ Strategies \\ (cf. Figure 1)}

1. Inquire about and acknowledge the athletes' feelings

\section{Description Explicit Skills From MAPS}

Open questions - active listening

Emotional response

Act in a warm and caring way
2. Supportive behaviours
3. Provide choice within specific rules and limits:
Show the athlete that you trust him/her

Task related support (avoid judgement and criticism)

Use "you may", "what do you think about." (minimize overt control should, have to)

Clarifiy responsibilities Involve the athlete in decision and solution finding processes Give the athlete real choices
Examples Coach Behaviours From Interviews

Learning Experience Following MAPS

Sometimes they are overwhelmed and come to me with their school-training conflicts - my job is to ask questions so they figure out themselves what to do. ... and meet them halfway.

There are solutions to most problems, if one athlete tells you that he/she is exhausted and in pain, which typically happens at camp, you simply suggest that they do another exercise or rest whatever is hurting.

One athlete had two weeks off training, and the first day back he complained about an important test and wanted to go home to study. We remembered the video and explained to him that he had not used his time off well enough and that we needed him back on the team.

The school structure is also something they need to acknowledge and understand how to adapt to and coordinate as both a student and an athlete. We need to teach them that from day one.

Athletes are responsible for their daily training as well as during vacations. We trust them. We ask the athletes to write their training log as a tool to them, not to control them.

Our trust allows the athletes to take responsibility. My best athletes take the most responsibility for their own training.

It is hard to see athletes who do not take responsibility for their own training. Instead of using the independent time to train, they chill out. My reaction to this is unfortunately to become more controlling and reduce time for independent training.

Sometimes, the athletes' initiatives need some guidance. One athlete had trained too hard and he needed us to help him plan differently.

There are consequences following broken rules. It is important to be very clear on the consequences of breaking rules. We have two athletes here who are on a short leash from partying during the season, something they know is breaking NTG code.

We involve our athletes in their long time development plans and short-time goals. Sometime they say they want to be the best, but they have no idea of what to do in the summer to reach their goals.

Instead of athlete involvement, I often end up giving them their plans,

One of my athletes was coming back from injury asking for drills and exercises. Based on previous drills - he chose his own drills.

Some athletes spend three years here without accepting the responsibilities.
Help them plan

Problem solving activities

Guidance to the right solution

Acknowledge and explain structure

Take responsibility

Broken trust requires clear structure

Balance support and guidance

Clear consequences (NTG context and following structure)

Explain to increase autonomy

Involve without response

Do not accept responsibilities
Trust the athletes 


\section{Need-Supportive \\ Strategies \\ (c. Figure 1)}

4. Provide a rational for task, limits and rules - structure

\section{Description Explicit} Skills From MAPS

Explain why you chose a specific exercise, tactic or rule Share knowledge about the sport
5. Allow athletes opportunities for initiative taking and independent work

6. Provide non-controlling competence feedback
Ask open questions Encourage initiative from the athletes
Factual non-judgmental feedback about problems Positive feedback that convey high but realistic expectations

Target behavior that are under the athletes' control - optimal challenge.
7. Facilitate self-improvement focus (prevent ego-involvement)
Focus on self-improvement Focus on mastery and effort in the group Self-set goals Give attention to all the athletes regardless of if they are doing well or struggle.

\section{Examples Coach Behaviours From Interviews}

We start out each season by explaining the importance of all the different classic training sessions.

Sometimes you have to put your foot down. One athlete told me it is not possible to run the 3000 meter three days after a big graduation party, however, party hard is not about the school's values.

It is a mistake to assume that the athletes understand the importance of training. They need an explaination for the reasons again and again. One often repeated question is why we do all the running.

The biggest challenge for us is when we explain why training is important, and they still do not believe you. The athletes seem to get a little confused if I ask them what they think and their opinions. They get better with practice. The intervention made me more aware of how I can help them feel confident enough to take more initiative.

This is an important strategy. Previously I have not done this the way I should, I have been afraid of their knowledge or lack there-of to make good decisions

To find the right answer can be really challenging, and they want it immidiately. I have become aware that I need I need more think time before I respond.

I have turned around the way I give feedback from saying what they do wrong (you are too far in the back) to tell them what they do well (you did work great with the arms and upper body position)

Giving great informative feedback requires you to be aware, pay attention, and think before you speek. The clue is to find the right solution for the inquiry or feedback situation at hand.

Central to the interaction with athletes at competitions is to discuss with the athletes what might be important focus points, it is a two way process.

It is much easier to ask them and focus on their own improvement when we work independently with athletes. On the roller-ski mill (treadmill for skis) for instance, I feel I have enough time to focus on self-improvement and also ask the athlete what her experience with or feeling about the technique is.

Every month we have independent meetings with all the athletes looking at their improvement and developmental key points. We also discuss their technical and tactical and physical goals with them

It is easier to give group feedback when the group is doing well or showing effort in the task. Talking to the ones that need it the most is natural, though the athletes that perform well sometimes think they get too little focus.

This is the most challenging strategy for me. When athletes get very disappointed, my solution is to ask them to mention three things they did well.

Sometimes after practice I find myself reflecting that I did not really handle the interaction with that athlete well.
Learning Experience

Following MAPS

Information about

training - maturity

You have to set the structure

Do not assuming they know

Not meaningful to the athlete

I can help the athletes feel confident in their decision making

Afraid of too much initiative

Find solutions for competence feedback

Increase competence feedback

Prioritizing focus areas

Feedback is a two-way process

Situation dependent

Increase athletes' awareness on self-improvement

Group dependent

Help athletes re-focus

Increased coach selfawareness 
structure when focusing on self-improvement by providing guidance for athlete development (Matosic et al., 2016; Skinner \& Edge, 2002). Coaches are encouraged to focus on mastery and effort in the group, which can nurture the athlete's need for competence, and autonomy (Mageau \& Vallerand, 2003; Tessier et al., 2010). Further, self-set goals help athletes experience success (Matosic et al., 2016; Taylor \& Ntoumanis, 2007), rather than goals that are related to comparisons with others, which is risky. For each athlete to feel success and competent in their endeavors, it is important to give all athletes attention, regardless of if they are doing well or struggle.

\section{A Short Presentation of MAPS}

MAPS was designed with a consideration of three recurring elements of successful interventions, and use of multiple types of media to deliver the content (Su \& Reeve, 2011). The first element consisted of group delivered information sessions in which basic tenets of SDT, types of motivation, and interpersonal style were presented. Second, coaches were presented empirical evidence for the adaptive outcomes associated with the supportive style. Third, every session in the intervention consisted of a section that was practice-oriented (group work activities, audio-visual clips, self-analysis). MAPS consisted of three workshops (two hours, two hours, one hour). Between the workshops, coaches had time for independent work with the digital workbook and continued experience-based learning to increase coaches' experience, so they could reach a higher level of leaning (Dreyfus \& Dreyfus, 1986; Dreyfus \& Dreyfus, 1980) throughout the intervention.

\section{The Workbook}

The participating coaches were presented with the digital workbook shortly after workshop 1. This workbook (34 pages) was available as an electronic media file and it was designed in line with the cognitive theory of multimedia learning to ensure coach learning (Mayer, 2009; Torgersen, 2012). The workbook content was divided into three parts. Part 1 explained postulates of SDT in the sport context: a) different types of athlete motivation; b) implications of motivational quality and motivational regulation; c) needs and the importance of need satisfaction; d) coaching styles and studies that demonstrate positive athlete outcomes from need supportive coaching. Part 2 presented the seven need-supportive coaching strategies: a) enumeration of the explicit coach behaviors; b) a video fragment that shows the practical application of the strategy in a sport context; c) examples of how they can use the strategy; d) implementation intentions; coaches were asked to think about how they can use the strategy in training and evaluate how it worked after training. Part 3 presented important determinants of need-supportive coaching: a) personal orientation; b) coaching context; c) perceptions of athlete behavior and motivation; and d) the complexity of coaching.

\section{The Video Fragments}

Each of the seven video fragments $(1.37-3.18$ minutes $)$ starts with a description of a need-supportive coaching strategy and a sport specific scenario is described by a voice-over, as we see athletes practicing while music is playing in the background. Next, we witness a dialogue between a coach and an athlete or a monologue by the coach. The coach behavior in each scenario is shown in a need-supportive way ("good coach") as well as a controlling way ("bad coach"). The videos end with a reflection by one of the athletes of how it felt to be coached by a predominantly needsupportive coach versus a predominantly controlling coach.

\section{Workshop 1: Multimedia Presentation}

The content of the first part of the workbook is presented as a 45 minute multimedia presentation, followed by a 15 minutes break. After the break, need-supportive strategies are presented to coaches, and the video fragment for each strategy is shown.

\section{Workshop 2: Presentation and Group Discussions}

The main theme of workshop 2 is to present and discuss antecedents of need-supportive coaching. Workshop 2 starts out with a recap of workshop 1, followed by a power-point presentation (approximately 30 minutes) on determinants of coach behavior (the digital workbook part 3): personal orientation, coach context, perception of athlete motivation, and the complexity of coaching. Coaches are organized in two groups and are given a few minutes to discuss each determinant in turn. The groups exchange their thoughts. Next, the educator asks coaches to discuss each of the need-supportive strategies in their appointed groups and share their experiences. The final part of workshop 2 is a reflection session in plenum on two statements; one on the importance of quality of motivation for young elite athletes, the other on control versus support.

\section{Workshop 3: One-on-One Sessions with the Educator}

In the final workshop, the educator meets with each coach for about an hour inquiring about their experiences with using the needsupportive strategies.

Perceived learning experiences for successful need-supportive coaching. All coaches $(\mathrm{n}=10)$ at one of the Norwegian College of Elite Sport (NTG) schools participated in the two-month long intervention. The coaches' working experiences ranged from no prior full-time coach experience to veterans with over 10-years of experience at NTG in addition to experience as a term national team coach $(\mathrm{M}=5.4, \mathrm{SD}=4.35)$. Semi-structured individual interviews with the coaches were conducted at NTG and lasted between 4964 minutes. The interviews focused on coaches' experiences with MAPS and their increased focus on need supportive behaviors by discussing their responses to the following questions: (1): how did you experience MAPS (workshop 1, 2 and 3), (2): To what extent did you use the digital workbook throughout the season? (3): To what extent have you (or not) changed the way you coach? (4): How could MAPS improve? (5): What was challenging? In the second part of the interview, a video-based method was used. Photo elicitation can be used in research to prompt responses and memory (Bryman, 2015; Harper, 2002; Pink, 2013). While watching each of the seven need-supportive videos, one at a time, the interviewer asked the coaches to think about examples of using "good-coach" and/or "bad-coach" strategies.

Rigor in the analysis process. Three strategies were used to establish rigor; thematic analysis, member reflection, and critical friends (Smith \& McGannon, 2018). First, we used an abductive, semantic version of the six step guidelines for thematic analysis (Braun, Clarke, \& Weate, 2016). Additionally, we e-mailed the coaches the article with their quotes. We received no corrections but many reflections on the content. The final strategy was to 
discuss the themes and codes and the reflexive acknowledgement of multiple truths with colleagues and other coaches to capture different perspectives in the research process.

Transcription of the interviews resulted in 88 pages. The first author familiarized herself with the data by reading and re-reading the raw data and making notes. This was the first step in the thematic analysis (Braun, Clarke, \& Weate, 2016). The extended version of the seven need-supportive strategies (Mageau \&Vallerand, 2003) were used to organize the raw data, and, as the text was read thoroughly, interesting features related to experiences with needsupportive coaching were systematically coded across the data-set (phase two: generating initial codes). Relevant data to each code were gathered and arranged in the text, and the research team discussed and systematically organized codes into themes in phase three. The emerging themes relating to coaches learning experiences with MAPS were reviewed (phase four), before discussion with a colleague helped verify themes with a final naming in phase five. The analyses ended with three main themes describing coaches learning experiences (inductive characteristic of the TA process). The final step was to select appropriate extracts, and the coaches' quotes were then linked to the seven need-supportive strategies (see Table 1). Based on the three main themes of successful giving of need-support, two distinctly different coach stories emerged.

\section{Impact of MAPS: Learning Experiences}

Summarizing coaches' learning experiences with MAPS, strategy 1 (inquire about and acknowledge the athlete's feelings) was regarded very important by all the coaches and requires coaches to spend time with each individual athlete. Strategy 2 (supportive behaviors) seemed to be difficult for some coaches due to a lack of trust in their athletes. Coach learning experiences with strategy 3 (provide choice within specific rules and limits) showed the importance of involving the athletes. Both for strategy 2 and 3, a gradual approach was recommended when athletes learn to make decisions and find solutions in their developmental process. Strategy 4 , to provide rationales to the athletes, was considered both challenging and important to develop. However, it was frustrating for several of the coaches to have to repeat themselves when explaining the "training is important" message to their athletes. Each situation and activity needs to be explained for a gradual development to take place. To be able to let go (strategy 5), was closely related to insecurity about the athletes' actual knowledge level and very sport specific. There was quite a range among the coaches' experiences with the program, depending of the sport, knowledge level, and maturity in their own development. The last two strategies were regarded central to coaching by all the coaches as they increase athletes' awareness of self-improvement. Finding enough time to invest in all athletes was a challenge. Based on this we suggested three dimensions for successful giving of needsupport to athletes that will be discussed below: time for each athlete, gradual approach, and carefully considering each specific situation.

\section{Discussion and Implications}

\section{Two Contradictory Stories Illustrating Coaches' Learning Experiences}

Two collective narratives (Clandinin \& Connelly, 2000) are presented to illustrate coaches' learning experiences with need- supportive strategies. The findings revealed a continuum of coach experiences from MAPS and the seven strategies, and the two narratives illustrate, three important dimensions for successful need-support. Coach 1 represents a coach-athlete interaction that is characterized by understanding and trust, while coach 2 tries out need supportive coaching with a non-understanding and resisting athlete.

Independent time with each athlete. For the coaches, the time spent with each individual athlete was a major factor in effective need-support, and it required commitment to invest sufficient time with each individual athlete. As coach 1 noted (strategy 7):

It is much easier to ask them to focus on their improvement when we work independently with athletes. On the roller-ski mill (treadmill for skis) for instance, I feel I have enough time to focus on self-improvement and ask the athlete what her experience with or feelings about the technique is.

MAPS had taught him a lot about how to give feedback in such situations. Despite that, coach 1 found it beneficial to have some "think time" before suggesting a solution to the challenge or inquiry at hand. This is because he had become more aware (intrapersonal) of his athletes' focus areas and how they evaluated the feedback, consequently, he wanted to streamline the feedback to each athlete. This also meant that coach 1 felt he had to be aware of the athlete's developmental process and spend enough time before each session with the athlete to "discuss what is the goal of the session, both technical and physically, which makes it much easier for me to talk about it later" (strategy 6). As the athlete learns and responds positively to the feedback, coach 1 also increases his effort.

In contrast, coach 2 who is generally dealing with athletes who lack understanding of the importance of training reported the process of offering competence feedback as more challenging (strategy 6 and 7). Even when prioritizing one-on-one time with athletes, discussions about development did not pay off, at least not at the time of the interview. For example, coach 2 added the following anecdote about athletes' lack of understanding about how to develop as snowboarders:

Two weeks ago, the athletes told me how important it was to practice in powder snow for their development and asked us to take them to an area with snow. After planning the trip, they did not want to come because they rather wanted to be at their home mountain practicing. Then they simply argued that practicing in powder snow would not help them become great snowboarders. This constant inconsistency in what they think helps, might be reduced with more discussions and what we learned from the program. However, this is time-consuming, challenging and we can hardly feel the progress.

The above example is all about involving athletes in the developmental process and making athletes commit to decisions. For example, last summer coach 2 did not ask about one of his athlete's summer-plans, and as a result, the summer training for this athlete was less than ideal. Through this experience and with the knowledge from MAPS, he had learned to inquire (strategy 1) better and involve the athlete in decision and solution finding processes (strategy 3) about his athletes' summer plan before they start the collective planning for next summer:

I think this year it is important that I ask her about her family's vacation plans before we plan so I can adjust to her current condition and summer plans with her family. I want her to tell 
me about her summer plan first, then she can suggest a plan for the summer, then we can make small adjustments and suggestions if we find it necessary.

Gradual approach. In the interviews, the coaches emphasized that they felt their athletes developed gradually, and as a result, their need-supportive behavior had to target the athletes as they were in that present situation. Hence, MAPS had raised the coaches' awareness of the fact that successful need-support is a gradual process. Following this line of thought, both coach 1 and 2 admitted that the first-year students at the elite sport school have yet to learn about physical, mental, technical and tactical development in their sport. The information about athletes' knowledge and understanding is important when considering the typically autonomy-supportive strategies; how to provide choice and involve the athletes (strategy 3), what to expect of athlete decision-making (strategy 2 - trusting the athlete and strategy 5 allow athletes opportunities for initiative taking and independent work), and sharing knowledge about the sport (strategy 4).

Coach 1 reflected that the best athletes are the most independent, they are better at taking responsibility and they are more "involved in their own development" (strategy 3). For instance, coaches need to let the athletes develop the skills they need to become autonomous in their own athletic development: "When we have individual meetings, we let them take charge and come with ideas. You can always come up with suggestions if they are really way of." The gradual approach will help athletes understand what is needed to take responsibility. As explained by coach 1: "The second and third year students mainly draft their own summer plan, we read it and together we revise the plan". This shows how when adapting a gradual approach and using the strategy (strategy 3 and 4), the athletes can take responsibility for their own training.

While coach 1 was having mature need-supportive discussion with autonomous athletes, how to develop different skills and be involved in their athletic development was at a completely different stage for coach 2. His starting point was: "they first of all need to learn what constitutes a good decision." Athletes with limited knowledge of the training process are likely to also lack understanding about, and thus not benefit from, need-supportive coaching. One classic example mentioned by coach 2 was the withdrawal of athletes' opportunity for individual training sessions in the fall: "We see that the level of understanding is too low, so to ensure quality of the physical training, we need to have as few individual sessions as possible" (not using strategy 2 and 3 ). With the tools from MAPS, coach 2 now admitted that he would need to start a gradual transfer of responsibility and increase the athletes' understanding of what is beneficial or not for them to do (strategy 4). He also admitted that he did expect them to already have this information at this level. To reach this goal, they now offer Tuesdayspeeches on training for their athletes: "National team coaches and athletes, other experts on different topics were brought in to explain to our athletes the importance of training".

In addition to these lectures, coach 2 - just like coach 1 -also tried to involve his athletes more in planning: "We try to involve the first-year student, but they do not really know what it means to be involved. So if you give them too many choices and decisions to make, they chose to take a break instead of doing what they can" (strategy 3). Through his learning experiences with the needsupportive strategies, workshops, and group discussions, coach 2 felt he had some tools to let go of his control and better practice a gradual approach to athlete development. When an athlete returned to on-snow training after injury and asked for drills, coach 2 started his gradual approach to initiative taking (strategy 5): "I asked him to think about drills he had used previously in practice. It was great when he chose his own drills".

Unfortunately, coach 2 wondered if they had in fact become more controlling throughout the season because the athletes' inability to earn their coaches' trust (strategy 2) and make good decisions (strategy 3). This made coaches struggle with need-support:

When our athletes are given the opportunity to take responsibility for their own on-snow training, and they have the opportunity to use the rails and practice different jumps without taking it, we simply have to decide for them. We explain to the athletes that we need them to be in the same park so we can give them feedback, but unfortunately, we end up with the same scenario and discussion the following day.

After attending MAPS, both coach 1 and 2 highlighted their new awareness on the importance of a gradual approach, although coach 2 experienced this as much more challenging than coach 1 .

A careful consideration of the specific situation. Both coach 1 and coach 2 noted that the use of need-supportive strategies was dependent on the situation at hand. Coaches are presented with a variety of situations ranging from everyday practice, school demands on their athletes, coaches' context demands on them, competition settings, group dynamics, the elite sport school context, national sport cultures, and so on. Coach 1 explained how he had to think about each situation to give the appropriate feedback (strategy 7). If an athlete starts to become uncertain about what to focus on during competition, he had to find a way to talk to the athlete, so he could focus on self-improvement: "I take the time to discuss what they need to keep their focus on in a specific situation."

However, simply using non-controlling competence feedback strategy is not always as easy as it sounds (strategy 6). The complexity of the situation influences the kind of feedback athletes need. Coach 2 perceived it as difficult to give feedback and attention to all the athletes (strategy 7). He used an example from the competition context:

Athletes react differently when failing, some want to talk but others prefer distance from me. It is individual when it is the right time to try to comfort them or give feedback. Because of this, I am better at giving feedback to the athletes who succeed. Before I found it hard to know when the right time for feedback is for the ones who fail. For example, it is not easy to find positive competence feedback if they ski out in the fifth gate. But you can say 'You really went for it out of the start.'

Summing up, the coach reflections reflect the need for coaches to develop an understanding for the three dimensions that determine the success of coach need-supportive behaviors, which in turn may be central to athletes' autonomous functioning and well-being. As seen from the examples illustrated in this discussion, athletes need to learn to "understand" what is needed to excel at the elite level. Athlete understanding is also important for how the coaches use the need-supportive strategies.

\section{Conclusion}

The impact evidence of learning experiences from MAPS, a theory-informed coaching development program, conveys that MAPS is helpful in teaching coaches about need-supportive skills 
at the intrapersonal (awareness of own coaching practice) and interpersonal (interaction with athletes) level. However, a successful implementation of need-supportive coaching also depends on the time one has for the individual athlete, a gradual approach of learning and autonomy, and a careful consideration of the specific situation. The test trial of the program revealed that MAPS is more successful with mature athletes (3rd year with an extensive knowledge of development) than with athletes who lack understanding both for development and why (how) to take initiative, be involved, and take responsibility for their own development (autonomy). The program needs to be revised to help coaches to be need-supportive for the latter group as well. As a final recommendation for future research, coach education developers and sports organizations should take into consideration athlete maturity to better optimize the program for different sports and age.

\section{Author Biographies}

Hedda Berntsen is a PhD-scholar at the Norwegian School of Sport Sciences. She has written three books, several chapters and chronicles, given speeches at international conferences and national sport federations. She has contributed to develop learning material for The Norwegian Ski Federation, and educating coaches. She is a former elite athlete with an Olympic silver medal in Ski Cross, World Champion Telemark skier, and bronze medalist in Alpine skiing.

Elsa Kristiansen is a professor at the University of South-Eastern Norway. She has published over 50 articles and book chapters in the areas of sport psychology (e.g., motivation, coping with stress, youth athletes) and sport management (e.g., volunteerism, YOG, event management, talent development). She was also a lecturer at one of the Norwegian top sport colleges for ten years.

\section{References}

Aelterman, N., Vansteenkiste, M., Van Keer, H., De Meyer, J., Van den Berghe, L., \& Haerens, L. (2013). Development and evaluation of a training on need-supportive teaching in physical education: Qualitative and quantitative findings. Teaching and Teacher Education, 29, 64-75. doi:10.1016/j.tate.2012.09.001

Allan, V., Vierimaa, M., Gainforth, H.L., \& Côté, J. (2017). The use of behaviour change theories and techniques in research-informed coach development programmes: A systematic review. International Review of Sport and Exercise Psychology, 11, 47-69. doi:10.1080/ 1750984X.2017.1286514

Amorose, A.J. (2007). Coaching effectiveness: Exploring the relationship between coaching behavior and self-determined motivation. In M.S. Hagger\& N.L.D. Chatzisarantis (Eds.), Intrinsic motivation and selfdetermination in exercise and sport (pp. 209-227). Champaign, IL: Human Kinetics.

Amorose, A.J., \& Anderson-Butcher, D. (2007). Autonomy-supportive coaching and self-determined motivation in high school and college athletes: A test of self-determination theory. Psychology of Sport and Exercise, 8(5), 654-670. doi:10.1016/j.psychsport.2006. 11.003

Balaguer, I., González, L., Fabra, P., Castillo, I., Mercé, J., \& Duda, J.L. (2012). Coaches' interpersonal style, basic psychological needs and the well-and ill-being of young soccer players: A longitudinal analysis. Journal of Sports Sciences, 30(15), 1619-1629. PubMed ID: 23062028 doi:10.1080/02640414.2012.731517
Braun, V., Clarke, V., \& Weate, P. (2016). Using thematic analysis in sport and exercise research. In B. Smith\& A. Sparkes (Eds.), Routledge handbook of qualitative research in sport and exercise (pp. 191-205). New York, NY: Routledge.

Bryman, A. (2015). Social research methods. Oxford, UK: Oxford University.

Calvo, T.G., Cervello, E., Jimenez, R., Iglesias, D., \& Murcia, J.A.M. (2010). Using self-determination theory to explain sport persistence and dropout in adolescent athletes. Spanish Journal of Psychology, 13(2), 677-684. doi:10.1017/S1138741600002341

Carpentier, J., \& Mageau, G.A. (2013). When change-oriented feedback enhances motivation, well-being and performance: A look at autonomy-supportive feedback in sport. Psychology of Sport \& Exercise, 14(3), 423-435. doi:10.1016/j.psychsport.2013.01.003

Clandinin, D.J., \& Connelly, F.M. (2000). Narrative inquiry: Experience and story in qualitative research. San Francisco, CA: Jossey-Bass.

Deci, E.L., \& Ryan, R.M. (1985). Intrinsic motivation and selfdetermination in human behavior. New York, NY: Plenum.

Deci, E.L., \& Ryan, R.M. (2000). The "what" and "why" of goal pursuits: Human needs and the self-determination of behavior. Psychological Inquiry, 11(4), 227-268. doi:10.1207/S15327965PLI1104_01

Deci, E.L., \& Ryan, R.M. (Eds.). (2002). Handbook of self-determination research. Rochester, NY: University of Rochester.

Evans, M.B., McGuckin, M., Gainforth, H.L., Bruner, M.W., \& Côté, J. (2015). Coach development programmes to improve interpersonal coach behaviours: A systematic review using the re-aim framework. British Journal of Sports Medicine, 49, 871-877. doi:10.1136/ bjsports-2015-094634

Fortier, M.S., Duda, J.L., Guerin, E., \& Teixeira, P.J. (2012). Promoting physical activity: Development and testing of self-determination theory-based interventions. International Journal of Behavioral and Nutrition and Physical Activity, 9(1), 20. doi:10.1186/14795868-9-20

Gilbert, W.D., \& Trudel, P. (2004). Analysis of coaching science research published from 1970-2001. Research Quarterly for Exercise and Sport, 75(4), 388-399. PubMed ID: 15673038 doi:10.1080/ 02701367.2004.10609172

González, L., Tomás, I., Castillo, I., Duda, J., \& Balaguer, I. (2017). A test of basic psychological needs theory in young soccer players: timelagged design at the individual and team levels. Scandinavian Journal of Medicine \& Science in Sports, 27(11), 1511-1522. doi:10.1111/ sms. 12778

Grouzet, F.M., Vallerand, R.J., Thill, E.E., \& Provencher, P.J. (2004). From environmental factors to outcomes: A test of an integrated motivational sequence. Motivation and Emotion, 28(4), 331-346. doi:10.1007/s11031-004-2387-z

Harper, D. (2002). Talking about pictures: A case for photo elicitation. Visual Studies, 17(1), 13-26. doi:10.1080/14725860220137345

Jang, H., Reeve, J., \& Deci, E.L. (2010). Engaging students in learning activities: It is not autonomy support or structure but autonomy support and structure. Journal of Educational Psychology, 102(3), 588-600. doi:10.1037/a0019682

Kristiansen, E., \& Roberts, G.C. (2010). Young elite athletes and social support: Coping with competitive and organizational stress in "Olympic" competition. Scandinavian Journal of Medicine \& Science in Sports, 20(4), 686-695. PubMed ID: 19793212 doi:10. 1111/j.1600-0838.2009.00950.x

Langdon, J., Harris, B.S., Burdette, G.P., III, \& Rothberger, S. (2015). Development and implementation of an autonomy supportive training program among youth sport coaches. International Sport Coaching Journal, 2(2), 169-177. doi:10.1123/iscj.2014-0068 
Lefebvre, J.S., Evans, M.B., Turnnidge, J., Gainforth, H.L., \& Côté, J. (2016). Describing and classifying coach development programmes: A synthesis of empirical research and applied practice. International Journal of Sports Science \& Coaching, 11(6), 887-899. doi:10.1177/ 1747954116676116

Mageau, G., \& Vallerand, R. (2003). The coach-athlete relationship: A motivational model. Journal of Sports Sciences, 21(11), 883-904. PubMed ID: 14626368 doi:10.1080/0264041031000140374

Matosic, D., \& Cox, A.E. (2014). Athletes' motivation regulations and need satisfaction across combinations of perceived coaching behaviors. Journal of Applied Sport Psychology, 26(3), 302-317. doi:10. 1080/10413200.2013.879963

Matosic, D., Ntoumanis, N., \& Quested, E. (2016). Antecedents of need supportive and controlling interpersonal styles from a selfdetermination theory perspective: A review and implications for sport psychology research. In M. Raab, P. Wylleman, R. Seiler, A.-M. Elbe \& A. Hatzigeorgiadis (Eds.), Sport and exercise psychology research (pp. 145-180). Amsterdam, Netherlands: Academic.

Norges Toppidrettsgymnas. (2018). Om NTG [about NTG]. Retrieved from http://ntg.no/artikkel/om-ntg

Ntoumanis, N. (2012). A self-determination theory perspective on motivation in sport and physical education: Current trends and possible future research directions. In G.C. Roberts\& D.C. Treasure (Eds.), Advances in motivation in sport and exercise (Vol. 3, pp. 91-128). Champaign, IL: Human Kinetics.

Pink, S. (2013). Doing visual ethnography. London, UK: Sage.

Reeve, J. (2013). How students create motivationally supportive learning environments for themselves: The concept of agentic engagement. Journal of Educational Psychology, 105(3), 579-595. doi:10.1037/ a0032690

Reeve, J., \& Jang, H. (2006). What teachers say and do to support students' autonomy during a learning activity. Journal of Educational Psychology, 98(1), 209-218. doi:10.1037/0022-0663.98.1.209

Reeve, J., Jang, H., Carrell, D., Jeon, S., \& Barch, J. (2004). Enhancing students' engagement by increasing teachers' autonomy support. Motivation and Emotion, 28(2), 147-169. doi:10.1023/B:MOEM. 0000032312.95499.6f

Ryan, R.M., \& Deci, E.L. (2017). Self-determination theory: Basic psychological needs in motivation, development, and wellness. New York, NY: Guilford.

Skinner, E., \& Edge, K. (2002). Parenting, motivation, and the development of children's coping. In L.J. Crockett (Ed.), Agency, motivation, and the life course: The Nebraska symposium on motivation (Vol. 48, pp. 77-143). Lincoln, NE: University of Nebraska.

Smith, A.L., Ntoumanis, N., Duda, J.L., \& Vansteenkiste, M. (2011). Goal striving, coping, and well-being: A prospective investigation of the self-concordance model in sport. Journal of Sport and Exercise Psychology, 33(1), 124-145. PubMed ID: 21451174 doi:10.1123/ jsep.33.1.124

Smith, B., \& McGannon, K.R. (2018). Developing rigor in qualitative research: Problems and opportunities within sport and exercise psychology. International Review of Sport and Exercise Psychology, 11(1), 101-121. doi:10.1080/1750984X.2017.1317357
Smith, R.E., Smoll, F.L., \& Cumming, S.P. (2007). Effects of a motivational climate intervention for coaches on young athletes' sport performance anxiety. Journal of Sport \& Exercise Psychology, 29(1), 39-59. PubMed ID: 17556775 doi:10.1123/jsep.29.1.39

Sparks, C., Dimmock, J., Whipp, P., Lonsdale, C., \& Jackson, B. (2015). "Getting connected": High school physical education teacher behaviors that facilitate students' relatedness support perceptions. Sport, Exercise, and Performance Psychology, 4(3), 219-236. doi:10.1037/ spy0000039

Standage, M., Gillison, F., \& Treasure, D.C. (2007). Self-determination and motivation in physical education. In M.S. Hagger \& N.L. Chatzisarantis (Eds.), Intrinsic motivation and self-determination in exercise and sport (pp. 71-86). Champaign, IL: Human Kinetics.

Stone, D.N., Deci, E.L., \& Ryan, R.M. (2009). Beyond talk: Creating autonomous motivation through self-determination theory. Journal of General Management, 34(3), 75-91. doi:10.1177/ 030630700903400305

Su, Y.L., \& Reeve, J. (2011). A meta-analysis of the effectiveness of intervention programs designed to support autonomy. Educational Psychology Review, 23(1), 159-188. doi:10.1007/s10648-010-9142-7

Taylor, I.M., \& Ntoumanis, N. (2007). Teacher motivational strategies and student self-determination in physical education. Journal of Educational Psychology, 99(4), 747-760. doi:10.1037/0022-0663.99.4.747

Tessier, D., Sarrazin, P., \& Ntoumanis, N. (2010). The effect of an intervention to improve newly qualified teachers' interpersonal style, students motivation and psychological need satisfaction in sportbased physical education. Contemporary Educational Psychology, 35(4), 242-253. doi:10.1016/j.cedpsych.2010.05.005

Turnnidge, J., \& Côté, J. (2017). Transformational coaching workshop: Applying a person-centred approach to coach development programs. International Sport Coaching Journal, 4(3), 314-325. doi:10.1123/ iscj.2017-0046

Vallerand, R.J. (1997). Toward a hierarchical model of intrinsic and extrinsic motivation. In M.S. Hagger\& N.L.D. Chatzisarantis (Eds.), Intrinsic motivation and self-determination in exercise and sport (pp. 255-279). Champaign, IL: Human Kinetics.

Vallerand, R.J., Fortier, M.S., \& Guay, F. (1997). Self-determination and persistence in a real-life setting: Toward a motivational model of high school dropout. Journal of Personality and Social Psychology, 72(5), 1161-1176. PubMed ID: 9150590 doi:10.1037/0022-3514.72.5.1161

Vallerand, R.J., \& Losier, G.F. (1999). An integrative analysis of intrinsic and extrinsic motivation in sport. Journal of Applied Sport Psychology, 11(1), 142-169. doi:10.1080/10413209908402956

Vallerand, R.J., Pelletier, L.G., \& Koestner, R. (2008). Reflections on selfdetermination theory. Canadian Psychology/Psychologie canadienne, 49(3), 257-262. doi:10.1037/a0012804

Vansteenkiste, M., \& Ryan, R.M. (2013). On psychological growth and vulnerability: Basic psychological need satisfaction and need frustration as a unifying principle. Journal of Psychotherapy Integration, 23(3), 263-280. doi:10.1037/a0032359

Vella, S.A., \& Perlman, D.J. (2014). Mastery, autonomy and transformational approaches to coaching: Common features and applications. International Sport Coaching Journal, 1(3), 173-179. doi:10.1123/ iscj.2013-0020 